\title{
Measurements and Studies of Harmonics and Switching Transients in Large HV Shunt Capacitor Banks
}

\author{
P. E. Issouribehere (*), F. Issouribehere (*), Member, IEEE, G. A. Barbera (*) and D. Gómez (**)
}

\begin{abstract}
Adding capacitors to an electric power system provides well known benefits, including power factor correction, voltage support and increase of active power transfer capacity. However, the capacitor banks modify the harmonic voltages and currents in the network and give rise to current and voltage transients, stressing switching devices and sensitive loads.

The first part of the paper describes measurements and studies performed before the installation of $2 \times 50$ MVAr capacitor banks in a 500-132 $\mathrm{kV}$ substation, in the Argentinian Transmission System. By measurements of harmonics content in voltage and current, the IITREE performed some studies to quantify the harmonic voltage in the $132 \mathrm{kV}$ busbar and the harmonic voltages and currents in the capacitors to prevent excessive overload. Switching Transients were also studied. The studies carried out with the Electromagnetic Transients Program (EMTP) are presented.

The second part of the paper deals with measurements performed after the installation of the $2 \times 50$ MVAr capacitor banks. These measurements were carried out to verify the harmonic levels in the busbar and in the capacitor bank, and to obtain the current and voltage switching transients. The results of measurements are compared to the ones obtained by studies and simulations.
\end{abstract}

Index Terms-Harmonics, THD, switching transients, inrush current, overvoltage, restrike, surge arresters.

\section{INTRODUCTION}

$\mathrm{S}$ hunt capacitors supply reactive power and boost local voltages. They are used throughout the system and are applied in a wide range of sizes. The principal advantages of shunt capacitors are their low cost and their flexibility of installation and operation. The main disadvantage of shunt capacitors is that their reactive power output is proportional to the square of the voltage. Consequently, the reactive power output is reduced at low voltages when it is most needed [1].

Shunt capacitors are used extensively in distribution systems for power-factor correction and feeder voltage control [2]. Shunt capacitors are also used to compensate the $X I^{2}$ losses in transmission systems and to ensure satisfactory voltage levels during heavy loading conditions. Capacitor banks are connected either directly to the high voltage bus or to the tertiary winding of the main transformer. Switching off capacitor banks provides a convenient means of controlling

$\left({ }^{*}\right)$ P. E. Issouribehere, F. Issouribehere and G. A. Barbera are with IITREELAT. Facultad de Ingeniería Universidad Nacional de La Plata (UNLP). (1900) 48 y 116. La Plata. Argentina (e-mail: iitree@iitree-unlp.org.ar).

(**) D. Gómez is with LEYDEN SA. (Medium voltage power capacitors Manufacturer). Anchoris 273 Buenos Aires, Argentina. (+54-11-43041056). Website: www.leyden.com.ar transmission system voltages. They are normally distributed throughout the transmission system so as to minimize losses and voltage drops. Detailed power-flow studies are performed to determine the size and location of capacitor banks to meet the system design criteria.

This paper presents measurements and studies performed before the installation of 2x50 MVAr capacitor banks in a 500-132 kV substation, in the Argentinian Transmission System. The studies performed predicted the harmonics levels in the $132 \mathrm{kV}$ busbar and in the capacitors. Switching transients, including energizing and de-energizing phenomena were also studied.

After the installation of the capacitor banks, the IITREE performed new measurements to verify the harmonics on the capacitors and in the $132 \mathrm{kV}$ busbar, and to verify the capacitor bank energizing and de-energizing transients.

The evaluation of the power quality of contemporary International and Argentinian standards is given, and the fundamental parameters of harmonic levels and switching transients are compared to reference values established by International Standards.

\section{Power System Configuration}

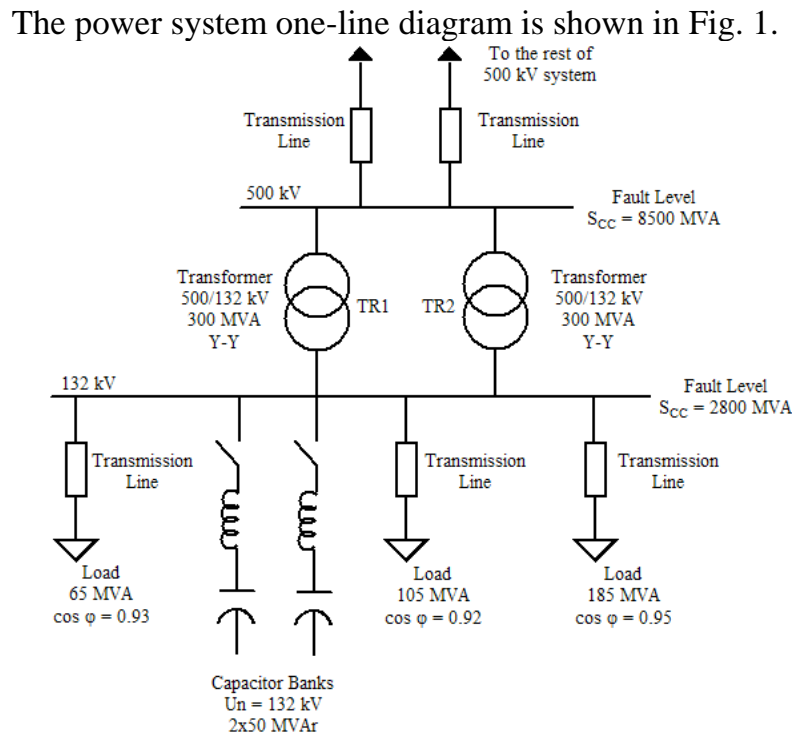

Fig. 1: One-line diagram of the power system.

The substation is composed by two 500/132 kV, 300 MVA transformers. The capacitor bank contains two $50 \mathrm{MVAr}$ fixed steps, for a total of $100 \mathrm{MVAr}$ at $132 \mathrm{kV}$. The technical installation specifications are shown in Table I to Table III. 